\title{
Mammalian soil disturbance, plant cover, and soil nitrogen in a prairie restoration
}

\author{
Helen M. Alexander ${ }^{1}$, Courtney Barnes ${ }^{1,2}$, Robert M. Timm ${ }^{1}$, And \\ Benjamin A. SiKes ${ }^{1,3}$
}

1. Department of Ecology and Evolutionary Biology, University of Kansas, Lawrence, Kansas halexander@ku.edu

2. Department of Biology, Northern Arizona University, Flagstaff, Arizona

3. Kansas Biological Survey, Lawrence, Kansas

\begin{abstract}
Small mammal disturbances in tallgrass prairies are known to influence a variety of ecosystem properties, including plant establishment, plant diversity, and soil nutrient dynamics. We explored direct and indirect effects of mammalian soil disturbance on a newly established grassland restoration site. In 2016-2017, we measured variation in small mammal soil disturbance, plant cover, and total inorganic nitrogen, all within the same plots. Within our site, interior plots had greater disturbance than plots located near site edges. On average, plots with high soil disturbance in 2016 had high disturbance in 2017, and disturbance in the first year was greater than in the second year. Soil disturbance was associated with an overall decline in grass cover and an increase in forb cover (especially Asteraceae). However, there were no associations between soil disturbance and either inorganic nitrogen or plant species richness/diversity on the new restoration site. Our study supports the important link between prairie plant communities and small mammal soil disturbance, potentially creating heterogeneity that is important for tallgrass prairie restoration and conservation.
\end{abstract}

Keywords: community composition; grasslands; inorganic nitrogen; rodents; tallgrass prairie

\section{INTRODUCTION}

Tallgrass prairie habitat and biodiversity has been largely lost from land conversion to agriculture and development. Grasslands are thus critically important for ecological restoration (Carbutt, Henwood, and Gilfedder 2017). Prairie restoration often focuses on plant communities (Foster et al. 2007; Brudvig 2011; Baer, Blair, and Collins 2016) as both indicators of restoration success and as ecological drivers. However animals and microbes may govern plant biodiversity and the ultimate success of restorations (Howe, Brown, and Zorn-Arnold 2002; McAlpine et al. 2016; Koziol and Bever 2017). For example, large mammals such as cattle and bison can maintain prairie plant biodiversity by suppressing dominant perennials (Hartnett, Hickman, and Walter 1996; Manning, Baer, and Blair 2017; Ruggiero and Kral 2018). Small mammals (moles, voles, prairie dogs, pocket gophers, and many others) also have major effects on grassland ecosystems (Whicker and Detling 1988; Howe et al. 2006: Questad and Foster 2007; Myster 2011; Moorhead et al. 2017). Presence of small mammals can directly alter plant community composition and diversity (Fig. 1, arrows $1 \mathrm{a}-1 \mathrm{c}, 2)$ and these changes can occur through at least two mechanisms. First, animal feeding patterns are important. For example, meadow voles (Microtus pennsylvanicus pennsylvanicus (Ord)) fed on above-ground plant biomass in a prairie experimental plot in Illinois (Howe et al. 2006). Some forb species (including Asteraceae) initially increased in abundance due to their unpalatability when exposed to voles, whereas grasses and other species decreased. These vegetation changes 
initially reduced plant diversity (Howe, Brown, and Zorn-Arnold 2002); over time, unpalatable species became abundant while palatable species persisted but at low levels (Howe et al. 2006). Granivory can also be important. Schneider et al. (2017) explored whether rodents preferred seeds of abundant non-native plants over more rare native planted species in a grassland restoration. In their study, although mammals consumed non-sown old field species (mostly non-native) most of the year, they still consumed seed of rare sown species, potentially negatively affecting restoration (Schneider et al. 2017).

Second, small mammals can lead to vegetation changes as a consequence of the actual burrowing and disturbance of soil. Such working of the soil can create areas with reduced abundance of long-lived competitive plant species and increased abundance of plant species that may be short-lived but are good colonists (Sousa 1984). This phenomenon is well known with prairie dogs, whose disturbance reduces grass cover and increases forb cover (Whicker and Detling 1988), although the outcomes are context dependent (Beals et al. 2014). Questad and Foster (2007) similarly found that vole disturbance influenced the plant community and soil nutrition on their burrowing sites, and soil disturbance caused by these mammals can contribute to greater spatial heterogeneity in vegetation (Yoshihara et al. 2010).

Small mammal effects on vegetation can also occur via indirect routes, such as through their effects on soil nutrients (Fig. 1, arrow 3). Nitrogen is one of the most limiting nutrients for plants (Vitousek 1982), and the most bioavailable forms of soil nitrogen for plants are nitrate and ammonium (Harrison, Bol, and Bargett 2007). However, nitrogen is also bound in less available organic forms, including plant litter and microbial necromass, which may necessitate microbial decomposition and mineralization to become available to plants (Harrison, Bol, and Bargett 2007). Small mammal burrowing mixes soil and litter layers, and can increase the rate of these microbial processes, making more inorganic nitrogen available to plants (Bakker et al. 2004, but see Moorhead et al. 2017). In addition, small mammal feces and urine can deposit significant quantities of nitrogen that rivals that of larger mammals (Bakker et al. 2004; Clark et al. 2005; Platt et al. 2016), and these may be important sources for plant communities.

Altering the abundance of available nitrogen, in turn, can have important effects on plant communities (Fig. 1, arrows 4a-c, 5). Increased nitrogen often has positive effects on plant growth, but within communities the sign and magnitude of nitrogen effects may depend on plant family or species. For example, high nitrogen soils may put legumes at a competitive disadvantage compared with grasses and other forbs (Borgström et al. 2017). Fertilization experiments have generally found that increasing nitrogen also decreases plant diversity (Fig. 1, arrow 5) (Foster and Gross 1998; Soons et al. 2017). In tallgrass prairies, nitrogen fertilization was associated with increased forb and decreased grass cover (Seastedt, Briggs, and Gibson 1991) whereas the opposite relationship was found in a serpentine annual grassland (Hobbs et al. 1998).

The above literature suggests that small mammals, plants, and nutrients are all interdependent within prairie systems. Howe, Brown, and Zorn-Arnold (2002) also emphasized the value of prairie restoration experiments to study plant-animal interactions. They hypothesized that remnant prairie grasslands may reflect the "ghost of vegetation past," and consist primarily of unpalatable species. In contrast, prairie restorations are likely to be composed of a diversity of plant species with regard to palatability. As a result, ecological effects of mammal feeding may be more apparent. We thus used an experimental tallgrass prairie restoration in northeast Kansas, USA to explore relationships between small mammal disturbance, vegetation, and 
soil nitrogen. Our work spanned two years and included measuring soil disturbance in late winter and plant cover and nitrogen in the following growing season (August or early September). We addressed specific relationships predicted in Fig. 1, asking whether soil disturbance predicted: 1) the abundance of particular plant families, 2) plant richness and diversity, or 3) total inorganic nitrogen (TIN) in the subsequent summer. We also explored if 4) changes in TIN were related to the dominance of plant families or 5) plant richness and diversity. Finally, from past work at this site, we knew that restoration sowing treatments differed in the percent cover and diversity of sown forb species (Jaksetic et al. 2018). We thus explored if any of the relationships shown in Figure 1 changed among experimental restoration treatments or between years.

\section{Materials and Methods}

Study Site: The study site is a $112 \mathrm{~m} \times 50 \mathrm{~m}$ ( $0.567 \mathrm{ha})$ tallgrass prairie restoration site in Lawrence, Kansas, USA ( $38^{\circ} 58^{\prime} 39.6^{\prime \prime} \mathrm{N}$, $\left.95^{\circ} 18^{\prime} 28.1^{\prime \prime} \mathrm{W}\right)$. It is located on a high school campus and was used as a football practice field from 1997 to 2012. In overview, the site was treated with herbicide to remove nonnative, cool season grasses in late 2013, and prairie grasses were drilled into the entire site in spring 2014 (10 species; seeding at an estimated rate of $8894.839 \mathrm{~g} \mathrm{PLS} / \mathrm{ha}$ ). Eighteen plots $(13.7 \mathrm{~m} \times 16.3 \mathrm{~m})$ were then established in three rows of six plots. Three different initial forb seeding treatments (six replicates/treatment) were assigned to plots using a modified Latin square design that allowed blocking in two directions (vertical and horizontal blocks). In six of the plots, no forb seed was sown $(\mathrm{G})$. In another six plots, a mixture of forb seed was sown at a rate

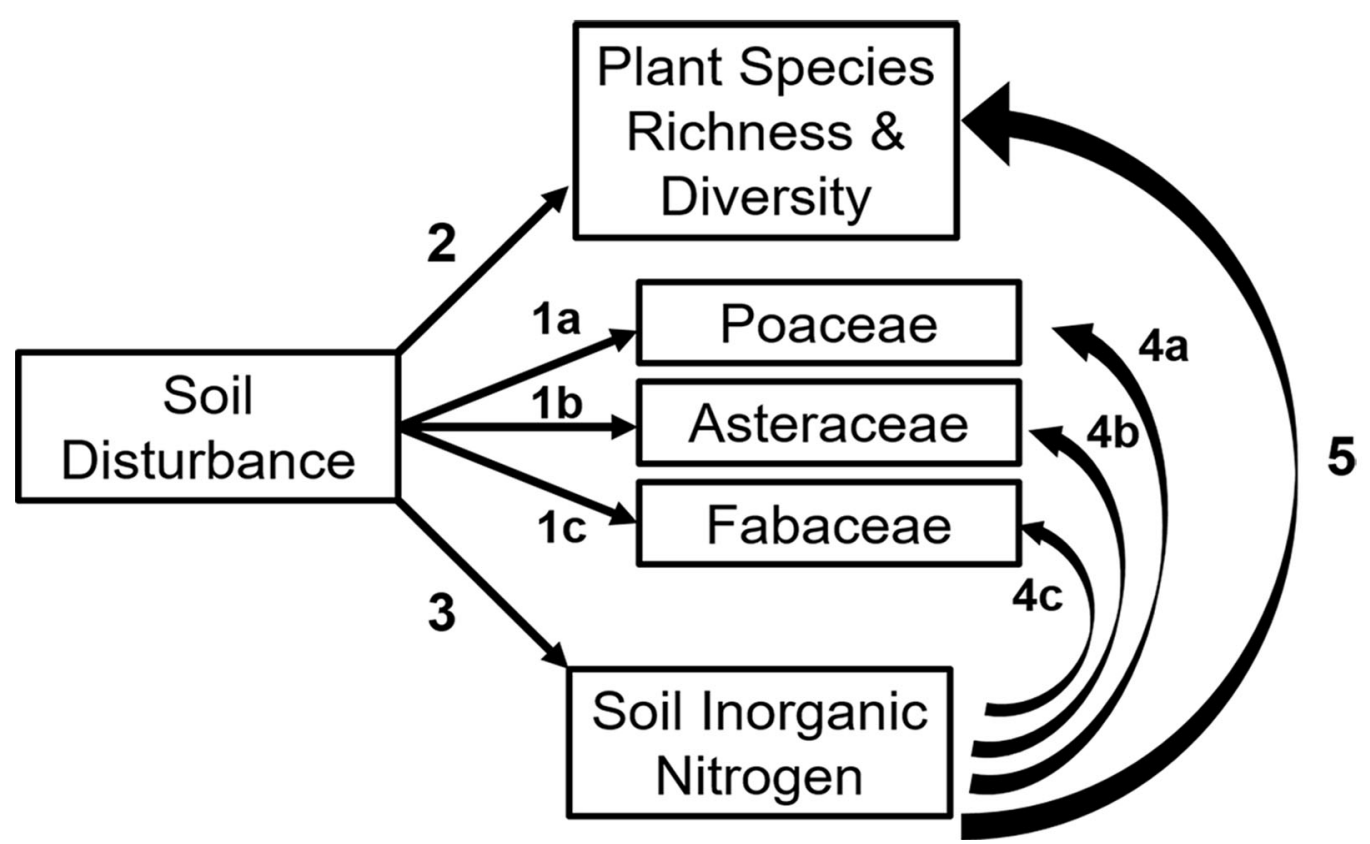

Figure 1: A conceptual diagram of effects of small mammal soil disturbance on plants through both direct and indirect mechanisms. Small mammals can affect particular plant families including Poaceae (arrow 1a), Asteraceae (arrow 1b), and Fabaceae (arrow 1c). They can also have impacts on the overall diversity of plant communities (arrow 2). However, small mammals also can affect the availability of inorganic nitrogen forms in the soil (arrow 3), and changes in nitrogen may enhance or counterbalance effects on individual plant functional groups (arrow 4a-c) or on overall plant diversity (arrow 5). 
typically used in prairie restorations (GF1). The final six plots had forb seed sown at twice the seeding density (GF2). The same seed mix (31 species) was used for both GF1 and GF2 plots with approximately 2,648.5 g PLS/ ha and 5297.14 g PLS/ha for the low and high seeding density plots respectively. The planting treatments thus differed in seeding density (GF2 > GF1 > G). See Fig. 2 and Jaksetic et al. (2018) for full details of the study.

Within each of the 18 treatment plots are four $1 \mathrm{~m} \times 1 \mathrm{~m}$ subplots (A-D) that we used for our 2016-2017 work on mammal soil disturbance, plant cover, and soil nitrogen. These subplots are centered in the four quadrants of the plots. In 2014, two of the subplots (B, C) were used in a separate study, where seedlings of five species were transplanted into a subplot with either soil from a remnant prairie or sterilized soil. With few exceptions, we thus only analyzed data from subplots A and D. Subplots $\mathrm{A}$ and $\mathrm{D}$ were $10 \mathrm{~m}$ apart from each other, diagonally. Studies of the 2015 vegetation in subplots A and D revealed greater sown forb cover, richness, and diversity in treatments GF1 and GF2 relative to G, as expected given the sowing treatments (Jaksetic et al. 2018).

During the time of our studies, the site consisted of a mixture of prairie plants and weedy species that were not sown. Dominant prairie grass species included Sorghastrum nutans (L.) Nash and Andropogon gerardii Vitman. Common prairie forbs were Coreopsis tinctoria Nutt., Monarda fistulosa L., Ratibida columnifera (Nutt.) Wooton \& Standl., Rudbeckia hirta L., and Salvia azurea Michx. ex. Lam. Non-sown weedy species included Conyza canadensis (L.) Cronquist and Ambrosia artemisifolia L.

The soil type of the area is clay loam consisting of sand and silt residuum weathered from shale and limestone on top a hardpan of bedrock. The site was leveled prior to the creation of a football field by adding soil from an unknown location. When used for high school sports, the field was periodically top dressed with

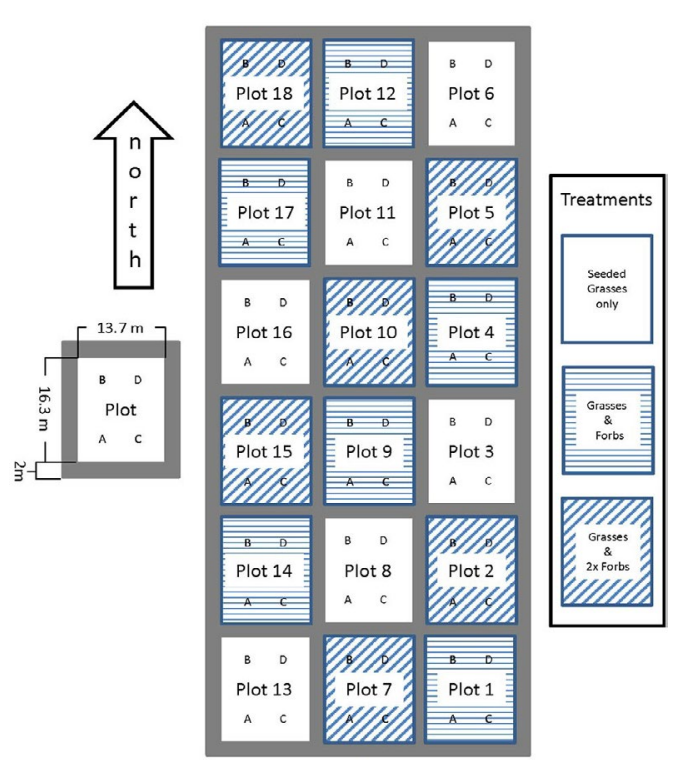

Figure 2: Experimental design and map of the prairie restoration study site in Lawrence, Kansas. The eighteen plots $(13.7 \mathrm{~m} \times 16.3 \mathrm{~m})$ were either seeded only with prairie grasses, with prairie grasses and with prairie forbs, or with prairie grasses and prairie forbs at twice the forb density. There were six replicates per treatment and a $2 \mathrm{~m}$ mown aisle between plots. Four $1 \mathrm{~m}$ $x 1 \mathrm{~m}$ subplots (A-D) were located in each plot.

black soil and sand and then grass seed added. There is no record of fertilizer additions.

Once the restoration was established, the area around the experimental plots was mowed ( 2 $\mathrm{m}$ aisles around each plot). Approximately $10-12 \mathrm{~m}$ away from the experimental plots are woodlands (two sides of the experiment) and a weedy field with scattered trees (one side of the experiment). On the remaining side of the experiment is a small prairie demonstration garden and a large high school sports field.

The total rainfall for March through August 2016 and 2017 was $72.75 \mathrm{~cm}$ and $64.46 \mathrm{~cm}$, respectively; the long-term average is $66.52 \mathrm{~cm}$ (U.S. Climate Data n.d.). Temperatures for this area for March through August 2016 and 2017 averaged $19.6^{\circ} \mathrm{C}$ and $18.6^{\circ} \mathrm{C}$, respectively. Long term averages for growing season temperatures are $18.2^{\circ} \mathrm{C}$ (U.S. Climate Data n.d.). 
Mammal Soil Disturbance: On 08-Mar-2016 and 09-Mar-2017, we quantified the percent cover of disturbed soil as a result of mammal disturbance in each of the subplots within all 18 plots. Disturbed soil was defined as soil that visually exhibited some type of mammal activity, including surface runways, burrowing, digging, and tunneling. We visually divided each meter squared plot into a $4 \times 4$ grid (16 squares, each $0.25 \mathrm{~m} \times 0.25 \mathrm{~m})$. We then recorded a number (0-16) as an estimate of the overall level of disturbance in the plot. For example, if approximately half of the subplot was disturbed by mammals, we recorded the number 8 . The common species of small mammals at the site were identified through assessing soil disturbance patterns (runways, tunneling, communal nest sites, food caches) and the characteristic clipping of plant material. Several species of small mammals could be found using the runways and tunnel systems made by other species. For example, cotton rat runs were frequently used by shrews, voles, and long-tailed mice; for our purposes here overall soil disturbance was quantified and thus we made no attempt to assign levels of disturbance to specific species.

Plant Cover: We collected percent cover plant data in the $1 \mathrm{~m} \mathrm{x} 1 \mathrm{~m}$ subplots on 16-17-Aug2016 and 30-Aug-1-Sep- 2017 following the methods described in Jaksetic et al. (2018). We visually determined the absolute percent cover of all species present in a plot. Since a species could occupy multiple levels of the canopy, total cover could exceed $100 \%$. In some cases, data were recorded to genus (e.g., Aster, Carex, Digitaria) due to difficulty in identifying species. We used the Shannon index in analyses of diversity.

Soil Nitrogen: On 13-Aug-2016 and 08-Aug2017, we extracted $2 \mathrm{~cm}$ diameter soil cores to a depth of $10 \mathrm{~cm}$ from the subplots A and D. In each subplot, three cores were taken approximately $30 \mathrm{~cm}$ apart and pooled into a single ziplock bag. These samples were kept in coolers and homogenized in the laboratory within $24 \mathrm{hrs}$. We homogenized each pooled sample by hand within the bag, so final analyses were based on
36 samples (18 plots, 2 subplots per plot). To determine soil moisture content prior to freezing, a $10 \mathrm{~g}$ subsample of each homogenized field sample was weighed, dried for 24 hours at $60^{\circ} \mathrm{C}$, and then reweighed. We recorded soil moisture within a week after soil extraction from the field. After recording soil moisture, the samples were frozen at $-20^{\circ} \mathrm{C}$ until further analysis.

To explore the connection between mammal disturbance and soil nitrogen, we analyzed two plant useable forms of nitrogen from each homogenized field sample. We extracted nitrogen from soil using the standard $\mathrm{KCl}$ method and quantified each sample using spectrophotometry (Keeney and Nelson 1982). Following chemical transformations, nitrate and ammonium concentrations were determined by spectrophotometry at $540 \mathrm{~nm}$ and 667 nm, respectively (Doane and Horwáth 2003). Standard protocols were used for microplate analysis of both nitrate and ammonium (Verdouw, Van Echiteld, and Dekkers 1978; Herman et al. 1995), with data corrected for differences in soil moisture. Our analyses focused on total inorganic nitrogen which, measured in ppm, is the sum of nitrate and ammonium concentrations in the soil samples.

Statistical Analyses: Our analyses focused on the two subplots (A and D) that were not part of the inoculation study noted in the Study Site section. Thus analyses were based on 36 subplots (18 plots, 2 subplots per plot). We first performed analyses of variance (Type III sums of squares) with response variables of 2016 and 2017 soil disturbance, absolute cover of all forbs, plant richness and diversity, or total inorganic nitrogen. We also explored absolute cover of two important prairie families in Fig. 1-Poaceae (grasses) and Asteraceae. Fabaceae (legumes) were too uncommon for analyses. Our models had three factors: vertical block, horizontal block, and planting treatment (G, GF1, and GF2), with plot as a random factor. For planting treatment, we followed Jaksetic et al. (2018) and focused on two a priori orthogonal contrasts: 1) treatments that differed 
in sown species diversity (G vs. GF1/GF2), and 2) treatments that differed in forb seeding density (GF1 vs. GF2). For all statistics, we defined alpha to be 0.05 and values greater than 0.05 but less than 0.10 to be marginally significant.

To examine associations shown by arrows in Figure 1 for both 2016 and 2017, we performed analyses of covariance (following the general approach used by Bever, Broadhurst, and Thrall (2013) on the same response variables noted above). Depending on the model, either soil disturbance or soil nitrogen was the covariate; our goal was to determine if these variables were predictors of response variables. In all cases, we focused on associations within a single year. For example, for arrow 1a, we analyzed 2016 grass cover with 2016 soil disturbance as a covariate (along with factors noted above), as well as the analogous analysis for 2017. Preliminary analyses also used a treatment*covariate interaction. However, interactions were only rarely significant and did not change interpretation of patterns so were not included in the final models. Data were transformed as needed; see Table 1 for details. Analyses were performed using SAS University Edition software (SAS Institute, Inc., Cary, NC).

All our plant analyses used both grasses and forbs with one exception. As explained in the Results, forb cover increased with mammal disturbance. Given this information, we performed analysis of covariance to explore whether mammal disturbance predicted greater cover of weedy forb species. We first coded plant species (both all forbs and Asteraceae) as either "weedy" or "not weedy." "Not weedy" plants were nearly all sown species and had coefficient of conservatism values $>2$ (these values reflect fidelity of species to preEuroAmerican settlement vegetation types, and high values reflect species usually restricted to native, undisturbed vegetation (Freeman 2012)). "Weedy" species included both nonnative and native species that readily colonize disturbed soil. We then used the proportion of weedy forbs or the proportion of weedy
Asteraceae (arcsin transformed) as response variables in analyses as described above.

Finally, we performed analysis of covariance as described above to determine if 2016 soil disturbance was a predictor of 2017 soil disturbance. To compare overall levels of mammal soil disturbance in 2016 and 2017, we used a paired $t$ test. We also compared average soil disturbance for exterior subplots (closest to the edge of the entire experiment) vs. interior subplots with a t test (this analysis was the only one that used all 72 subplots (18 plots, 4 subplots (A-D) per plot). Mean levels of disturbance are presented with \pm standard error.

\section{RESUlts}

Mammal species: Small mammals fairly quickly colonized the restored prairie. Seeding of prairie vegetation occurred in spring 2014 and by summer 2016 the common species of native mammals in the region had colonized throughout the site. These include the prairie vole (Microtus ochrogaster Wagner), hispid cotton rat (Sigmodon hispidus Say and Ord), eastern mole (Scalopus aquaticus L.), and short-tailed shrew (Blarina hylophaga Elliot). Almost certainly one or both local species of deer mice (Peromyscus leucopus Rafinesque and $P$. maniculatus Wagner), least shrews (Cryptotis parvus Say), and eastern cottontail rabbits (Sylvilagus floridanus J. A. Allen) were present at least occasionally on the plots. In 2016, prairie voles were judged especially abundant. Conversely, in 2017 hispid cotton rats were more common than prairie voles. Mole disturbance was essentially the same both years and probably represented only a few individuals, although their subsurface feeding tunnels ran for a considerable distance $(>100$ $\mathrm{m})$ and were responsible for significant soil disturbance.

Mammal soil disturbance: Soil disturbance levels did not differ among seeding treatments in either 2016 or 2017 , but 2016 soil disturbance levels were a positive predictor 
Table 1: Analyses of 2016 percent cover (Poaceae, Asteraceae, all forbs), plant richness, plant diversity, and total nitrogen with a covariate of soil disturbance. Factors include vertical block, horizontal block, and treatment; the covariate was the extent of soil disturbance. The coefficient shows whether the relationship between the response variable and the covariate is positive or negative. For treatment, two a priori orthogonal contrasts were performed. G vs. GF12 refers to an a priori orthogonal contrast of the prairie grass only sowing treatment versus the two sowing treatments with grass and forbs (GF1, GF2). GF1 vs. GF2 refers to an a priori orthogonal contrast of the two sowing treatments that differed in forb density (GF1, GF2). Data were log transformed for analyses on Asteraceae and total nitrogen.

\begin{tabular}{|c|c|c|c|c|c|c|}
\hline & Poaceae & Asteraceae & All Forbs & Richness & Diversity & Total N \\
\hline \multirow[t]{2}{*}{ Vertical block } & $F_{5,8}=1.98$ & $F_{5,8}=0.81$ & $F_{5,8}=0.62$ & $F_{5,8}=0.27$ & $F_{5,8}=0.28$ & $F_{5,8}=0.34$ \\
\hline & $P=0.187$ & $P=0.5713$ & $P=0.6895$ & $P=0.9162$ & $P=0.9087$ & $P=0.8719$ \\
\hline \multirow[t]{2}{*}{ Horizontal Block } & $F_{2,8}=2.12$ & $F_{2,8}=1.00$ & $F_{2,8}=0.35$ & $F_{2,8}=1.75$ & $F_{2,8}=0.56$ & $F_{2,8}=5.24$ \\
\hline & $P=0.183$ & $P=0.4091$ & $P=0.7141$ & $P=0.2346$ & $P=0.5900$ & $P=0.0305$ \\
\hline \multirow[t]{2}{*}{ Treatment } & $F_{2,8}=4.46$ & $F_{2,8}=2.40$ & $F_{2,8}=1.35$ & $F_{2,8}=1.00$ & $F_{2,8}=0.37$ & $F_{2,8}=0.11$ \\
\hline & $P=0.050$ & $P=0.1530$ & $P=0.3128$ & $P=0.4097$ & $P=0.7035$ & $P=0.8930$ \\
\hline \multirow[t]{2}{*}{ G vs. GF12 } & $F_{1,8}=8.78$ & $F_{1,8}=4.66$ & $F_{1,8}=2.58$ & $F_{1,8}=1.50$ & $F_{1,8}=0.69$ & $F_{1,8}=0.23$ \\
\hline & $P=0.181$ & $P=0.0628$ & $P=0.1468$ & $P=0.2558$ & $P=0.4292$ & $P=0.6447$ \\
\hline \multirow[t]{2}{*}{ GF1 vs. GF2 } & $F_{1,8}=0.17$ & $F_{1,8}=0.13$ & $F_{1,8}=0.11$ & $F_{1,8}=0.51$ & $F_{1,8}=0.69$ & $F_{1,8}=0.00$ \\
\hline & $P=0.694$ & $P=0.7252$ & $P=0.7464$ & $P=0.2558$ & $P=0.4292$ & $P=0.9991$ \\
\hline \multirow[t]{3}{*}{ Covariate } & Disturbance & Disturbance & Disturbance & Disturbance & Disturbance & Disturbance \\
\hline & $F_{1,17}=5.95$ & $F_{1,17}=10.58$ & $F_{1,17}=3.80$ & $F_{1,17}=3.41$ & $F_{1,17}=0.13$ & $F_{1,17}=0.23$ \\
\hline & $P=0.026$ & $P=0.0047$ & $P=0.0678$ & $P=0.0821$ & $P=0.7221$ & $P=0.6551$ \\
\hline Coefficient & -2.5009 & 0.1067 & 2.3352 & 0.1964 & 0.006409 & -0.00940 \\
\hline
\end{tabular}

of 2017 levels (Fig. 3). Overall, the average number of $0.25 \mathrm{~m} \mathrm{x} 0.25 \mathrm{~m}$ disturbed squares was greater in $2016(8.28+0.74)$ than 2017 $\left(6.03+0.50\right.$; paired t-test, $\mathrm{t}_{35}=3.7, \mathrm{P}=$ $0.001)$. Given that complete disturbance was defined as 16 out of 16 squares per subplot being affected, this means that average 2016 disturbance was $\sim 52 \%$ compared to $\sim 38 \%$ for 2017. In 2017, we observed greater amounts of soil disturbance in interior plots compared to plots on the edge of the restoration site; similar patterns were observed in 2016 (2016: interior $=8.92+0.72$; exterior $=6.94+0.75, \mathrm{t}_{70}=$ $-1.90, \mathrm{P}=0.062 ; 2017$ : interior $=7.27+0.47$; exterior $=4.88+0.55, \mathrm{t}_{70}=-3.35, \mathrm{P}=0.002$ ).
Plant cover: In 2016, greater levels of soil disturbance were associated with less grass cover (Poaceae). (Table 1, Fig. 4a). Cover of Asteraceae was positively associated with soil disturbance (Table 1, Fig. 4b), and a similar pattern (marginally significant) was found for all forbs (Table 1). Additionally, soil disturbance was positively related to plant richness (marginally significant), but not diversity (Table 1). We found no evidence that the proportion of weedy forbs or weedy species in the Asteraceae were associated with soil disturbance. In 2017, there were no significant relationships between soil disturbance and percent cover of grasses, all forbs, or 


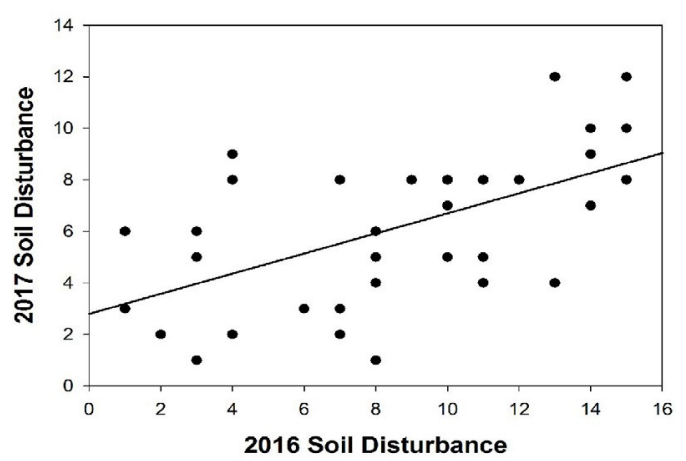

Figure 3: Relationship between levels of soil disturbance in 2016 and 2017. Each symbol refers to data from one of the 36 subplots (1 $\mathrm{m} \times 1 \mathrm{~m}$ ) in a prairie restoration experiment in Lawrence, Kansas; $R^{2}=0.33$. Soil disturbance was estimated in 16 squares $(0.25 \mathrm{~m} \times 0.25$ m) for each subplot in March 2016 and 2017; a value of 8 means that half of the soil area was disturbed.

Asteraceae. Similarly, species richness and diversity exhibited no patterns with respect to soil disturbance. In general, we observed few effects of the restoration treatment. In analyses of Asteraceae with a covariate of disturbance, the GF1 and GF2 treatments had greater cover by Asteraceae and forbs in 2017 than the $G$ treatment, with a similar marginally significant pattern in 2016 for Asteraceae (Table 1).

Soil nitrogen: In both 2016 (Table 1) and 2017, soil disturbance was not associated with total inorganic nitrogen content in soils. Nitrogen also had no association with total cover, plant community composition, species richness, or vegetation.

\section{Discussion}

Interest in the biological reworking of soils dates back to Darwin and continues today (Meysman, Middelburg, and Heip 2006; Coggan, Hayward, and Gib 2018). In our research, small mammal soil disturbance in an experimental prairie restoration was associated with an increase in forbs (especially Asteraceae) and a decrease in grasses during the first year of our study. Our results are generally consistent with several
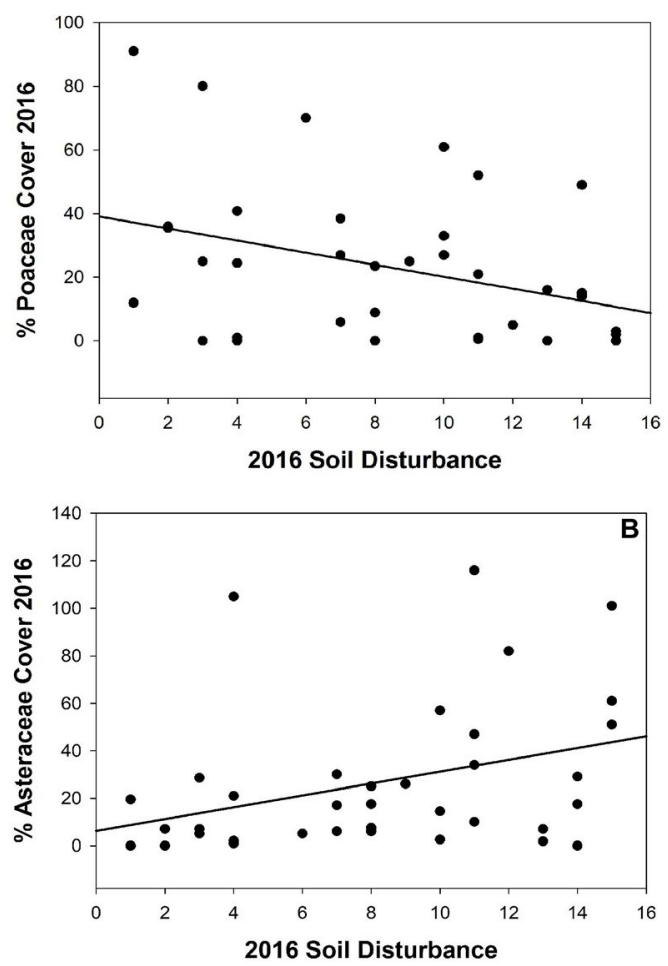

Figure 4: 2016 relationships between small mammal soil disturbance and a) percent cover of plants in the Poaceae and b) percent cover of plants in the Asteraceae. Each symbol refers to data from one of the 36 subplots $(1 \mathrm{~m} \times 1 \mathrm{~m})$ in a prairie restoration experiment in Lawrence, Kansas; $R^{2}$ for both $a$ ) and $b$ ) $=0.12$. Soil disturbance was estimated in 16 squares $(0.25$ $\mathrm{m} \times 0.25 \mathrm{~m}$ ) for each subplot in March 2016 and 2017; a value of 8 means that half of the soil area was disturbed. Plant percent cover was estimated in August - early September of 2016 and 2017.

animal exclusion experiments (Howe et al. 2006; Myster 2011; Moorhead et al. 2017) even though animal movement was not restricted in our study. We found no evidence that small mammal soil disturbance was linked to greater colonization of early successional plant species.

Overall, we found temporal consistency in patterns of soil disturbance across space. We observed, for example, that subplots with high soil disturbance in 2017 had high soil disturbance in 2016. Likely explanations 
might include animals using the same nest site and runways from year to year and that soil disturbance visible in one year may still be visible in subsequent years. Cotton rat and prairie vole nests in the Great Plains can be stable over a few years, and even in abandoned nests, the soil disturbance might take months to break down (R. Timm, pers. obs.). Our observations suggest a shift in animal species abundance between years (more hispid cotton rats and fewer prairie voles) and levels of disturbance were less the second year. These factors may explain why overall patterns (decline in Poaceae and increase in Asteraceae with soil disturbance) were similar in both years, although not statistically significant in 2017 . We did not record soil disturbance patterns in the first years of the restoration (2014-2015); we thus do not know whether animal disturbance patterns established in early years have been maintained or not. Repeated disturbance over multiple years, however, may contribute to stronger spatial heterogeneity in plant communities than individual disturbance events (Bryce et al. 2013).

Considerable year-to-year and seasonal variation in numbers of both cotton rats and prairie voles are well documented in northeastern Kansas (Timm, Pisani, and Slade 2015). Cotton rat populations in Kansas can reach 100 individuals per hectare and prairie voles as high as 200 per hectare (Timm, Pisani, and Slade 2015). These high numbers are then generally followed by population crashes. Prairie voles are known to store food caches underground, whereas cotton rats probably do not (Timm, Pisani, and Slade 2015). Although cotton rats, prairie voles, and eastern cottontails are considered "grassfeeding herbivores," and the shrews and moles "insectivores," these species regularly feed on mixed seed at bird feeders during the winter months in Kansas. Their regular use of seeds (especially sunflower, milo, and cracked corn) throughout winter months suggests that seed consumption by these species in a more natural situation is common (R. Timm, pers. obs.). The combination of soil disturbance, grazing on both above ground vegetation and roots, and the consumption of seeds suggest that the small mammal community can play a critical role in shaping prairies and in restoration efforts.

We found no relationship between naturally occurring variation in available nitrogen, soil disturbance, and vegetation. There are several possible reasons for the lack of patterns. First, soil data come from cores taken throughout the $1 \mathrm{~m}^{2}$ subplot so that our soil data reflected the subplot-based plant cover data. However, even "high" disturbance subplots typically did not have soil disturbance throughout the entire area so nitrogen data in such plots may come from soil that was both disturbed and not disturbed by animals. Our methodology thus differs from work done with similar mammals at a site 17 $\mathrm{km}$ away where sampling was done explicitly on and off vole burrows, and where effects of mammal disturbance were more pronounced (Questad and Foster 2007). Second, soil nitrogen was measured at the height of plant growth, but this was six months after soil disturbance was quantified. Animal use of runways, burrows, and nest sites tended to be fairly stable for months; our soil disturbance, $\mathrm{N}$ data, and plant cover were effectively "snapshots" of ongoing processes, but provided a good approximation. We noted that soil disturbance can be most easily quantified in winter months when above ground plant parts were dead or dormant. Third, increased soil disturbance may not immediately increase plant-available nitrogen in the presence of other organisms. Previous findings that mineralized $\mathrm{N}$ increased in the presence of small mammals was linked to plant community changes from cattle exclusion (Bakker et al. 2004). Elsewhere burrowing disturbance alone increased ammonium, but did not increase total inorganic nitrogen (Moorhead et al. 2017). Any $\mathrm{N}$ increases from mammal disturbance may be relatively small (e.g., compared to fertilization experiments) or rapidly taken up by microbial communities (Porras-Alfaro et al. 2007) before plants can access it. Over time this nitrogen 
should make its way into the plant system (Harrison, Bol, and Bardgett 2007) so the relative young age of this prairie restoration (and small mammal colonization) may contribute to the lack of effects. We do not have data on plant biomass so cannot explore whether nitrogen associated with mammalian soil disturbance led to greater plant growth. Future studies can more effectively assess different nitrogen pools, including inorganic $\mathrm{N}$ species in soil, microbial biomass $\mathrm{N}$, and $\mathrm{N}$ taken up into plant tissues, and study these over a longer time span.

Our study was done in the context of a restoration experiment - prairie grasses (10 species) had been sown across the entire site. In one treatment, no prairie forbs had been sown while in the other two treatments, 31 prairie forb species had been added at one of two densities. Despite large differences in both total and sown cover species, plant richness, and plant diversity between these treatments (Jaksetic et al. 2018), we saw little evidence that soil disturbance differed among treatments. We did observe spatial variation in disturbance, with greater disturbance in the interior of the $3 \times 6$ array of plots, as opposed to those close to the exterior edge of the entire experiment. Animals may be preferentially selecting interior areas rather than edges, perhaps because of greater food resources or cover. Spatial variation in herbivory can affect plant community composition: Germain et al. (2013), for example, suggested that spatial variation in granivory affected whether deterministic or stochastic factors affected community assembly in a tallgrass prairie experiment.

In conclusion, we found that soil disturbance was associated with reduced grass cover and more cover by plants in the Asteraceae (Fig. 1, arrows 1a, b). However, we did not find strong support for simple linkages between small mammal disturbance, nitrogen, and vegetation (plant composition, richness, and diversity) (Fig. 1, arrows 2,3,4,5) during the two summers when populations of the small mammals were at moderate levels. We note, however, the impact of small mammals on plant communities has potential restoration implications: plant feeding by small mammals may be important to suppress prairie grasses that often dominate restorations (McCain et al. 2010) and their granivory can have important consequences for establishment of sown plant species (Schneider et al 2017; Pellish et al. 2018). We encourage future research to integrate both direct and indirect mechanisms when assessing small mammal impacts on vegetation.

\section{ACKnowledgments}

We thank Julie Schwarting, Free State High School, and the Elizabeth Schultz Environmental Fund for helping establish and maintain the prairie restoration experiment. We also thank Drs. Bryan Foster, Terry Loecke, and James Bever for advice and assistance to obtain plant data, nitrogen data, and statistical analyses respectively. Courtney Barnes was supported by an Undergraduate Research Fellowship Award from the University of Kansas. The research was also partially supported by NSF0070876 to Benjamin Sikes.

\section{Literature Cited}

Baer, S.G., Blair, J.M., and Collins, S.L. 2016.

Environmental heterogeneity has a weak effect on diversity during community assembly in tallgrass prairie. Ecological Monographs 86:94-106.

Bakker, E.S., Olff, H., Boekhoff, M., Gleichman, J.M., and Berendse, F. 2004. Impact of herbivores on nitrogen cycling: contrasting effects of small and large species. Oecologia 138:91-101.

Beals, S.C., Hartley, L.M., Preve, J.S., and Seastedt, T.R. 2014. The effects of black-tailed prairie dogs on plant communities within a complex urban landscape: An ecological surprise? Ecology 95:1349-1359.

Bever, J.D., Broadhurst, L.M., and Thrall, P.H. 2013. Microbial phylotype composition and diversity predicts plant productivity and plant-soil feedbacks. Ecology Letters 16:167-174. 
Borgström, P., Strengbom, J., Marini, L., Viketoft, M., and Bommarco, R. 2017. Above- and belowground insect herbivory modifies the response of a grassland plant community to nitrogen eutrophication. Ecology 98:545-554.

Brudvig, L.A. 2011. The restoration of biodiversity: where has research been and where does it need to go? American Journal of Botany 98:549-558.

Bryce, R., van der Wal, R., Mitchell, R., and Lambin, X. 2013. Metapopulation dynamics of a burrowing herbivore drive spatio-temporal dynamics of riparian plant communities. Ecosystems 16:1165-1177.

Carbutt, C., Henwood, W.D., and Gilfedder, L.A. 2017. Global plight of native temperate grasslands: going, going, gone? Biodiversity and Conservation 26:2911-2932.

Coggan, N.V., Hayward, M.W., and Gib, H. 2018. A global database and "state of the field" review of research into ecosystem engineering by land animals. Journal of Animal Ecology 87:974-994.

Clark, J.E., Hellgren, E.C., Parsons, J.L., Jorgensen, E.E., Engle, D.M., and Leslie, Jr., D.M. 2005. Nitrogen outputs from fecal and urine deposition of small mammals: implications for nitrogen cycling. Oecologia 144:447-455.

Doane, T.A.and Horwáth, W.R. 2003.

Spectrophotometric determination of nitrate with a single reagent. Analytical Letters 36:2713-2722.

Foster, B.L. and Gross, K.L. 1988 Species richness in a successional grassland: effects of nitrogen enrichment and plant litter. Ecology 79:2593-2602.

Foster, B.L., Murphy, C.A., Keller, K.R., Aschenbach, T.A., Questad, E.J., and Kindscher, K. 2007. Restoration of prairie community structure and ecosystem function in an abandoned hayfield: a sowing experiment. Restoration Ecology 15:652-661.

Freeman, C.C. 2012. Coefficients of conservatism for Kansas vascular plants and selected life history attributes. http://kars. ku.edu/media/ksnhi/public-data-resources/ Explanation of Coefficients of Conservatism for Kansas Vascular Plants (2012).pdf.
Germain, R.M., Johnson, L., Schneider, S., Cottenie, K., Gillis, E.A., and MacDougall, A.S. 2013. Spatial variability in plant predation determines the strength of stochastic community assembly. American Naturalist 182:169-179.

Harrison, K.A., Bol, R., and Bardgett, R.D. 2007. Preferences for different nitrogen forms by coexisting plant species and soil microbes. Ecology 88:989-999.

Hartnett, D.C., Hickman, K.R., and Walter, L.E.F. 1996. Effects of bison grazing, fire, and topography on floristic diversity in tallgrass prairie. Journal of Range Management 49:413-420.

Herman, D.J., Brooks, P.D., Ashraf, M., Azam, F., and Mulvaney, R.L. 1995. Evaluation of methods for nitrogen-15 analysis of inorganic nitrogen in soil extracts. II. Diffusion methods. Communications in Soil Science and Plant Analysis 26:1675-1685.

Hobbs, R.J., Gulmon, S.L., Hobbs, V.J., and Mooney, H.A. 1988. Effects of fertiliser addition and subsequent gopher disturbance on a serpentine annual. Oecologia 75:291-295.

Howe, H.F., Brown, J.S., and Zorn-Arnold, B. 2002. A rodent plague on prairie diversity. Ecology Letters 5:30-36.

Howe, H.F., Zorn-Arnold, B., Sullivan, B., and Brown, J.S. 2006. Massive and distinctive effects of meadow voles on grassland vegetation. Ecology 87:3007-3013.

Jaksetic, N., Foster, B.L., Bever, J.D., Schwarting, J, and Alexander, H.M. 2018. Sowing density effects and patterns of colonization in a prairie restoration. Restoration Ecology 26:245-254.

Keeney, D.R. and Nelson, D.W. 1982. Nitrogeninorganic forms. Pp. 643-698 in Methods of Soil Analysis, Part 2, Chemical and Microbiological Properties, no. Second Edition. Soil Science Society of America.

Koziol, L. and Bever, J.D. 2017. The missing link in grassland restoration: arbuscular mycorrhizal fungi inoculation increases plant diversity and accelerates succession. Journal of Applied Ecology 54:1301-1309. 
Manning, G.C., Baer, S.G., and Blair, J.M. 2017. Effects of grazing and fire frequency on floristic quality and its relationship to indicators of soil quality in tallgrass prairie. Environmental Management 60:1062-1075.

McAlpine, C., Catterall, C.P., Mac Nally, R., Lindenmayer, D., Reid, J.L., Holl, K.D., Bennett, A.F., Runting, R.K., Wilson, K., Hobbs, R.J., Seabrook, L., Cunningham, S., Moilanen, A., Maron, M., Shoo, L., Lunt, I., Vesk, P., Rumpff, L., Martin, T.G., Thomson, J., and Possingham, H. 2016. Integrating plant-and animal-based perspectives for more effective restoration of biodiversity. Frontiers in Ecology and the Environment 14:37-45.

McCain, K.N.S., Baer, S.G., Blair, J.M., and Wilson, G.W.T. 2010. Dominant grasses suppress local diversity in restored tallgrass prairie. Restoration Ecology 18:40-49.

Meysman, F.R., Middelburg, J.J., and Heip, C.H.R. 2006. Bioturbation: a fresh look at Darwin's last idea. Trends in Ecology and Evolution 21:688-695.

Myster, R.W. 2011. Above-ground vs. below-ground interactive effects of mammalian herbivory on tallgrass prairie plant and soil characteristics. Journal of Plant Interactions 6:283-290.

Moorhead, L.C., Souza, L., Habeck, C.W., Lindroth, R.L., and Classen, A.T. 2017. Small mammal activity alters plant community composition and microbial activity in an old-field ecosystem. Ecosphere 8(5):e01777. 10.1002/ecs2.1777.

Pellish C. A., Sherrard, M. E., Leytem, P.A., and Jackson, L. L. 2018. Small vertebrate granivores reduce seedling emergence in native tallgrass prairie restoration. Restoration Ecology 2:323-330.

Platt, B.F., Kolb, D.J., Kunhardt, C.G., Milo, S.P., and New, L.G. 2016. Burrowing through the literature: The impact of soil-disturbing vertebrates on physical and chemical properties of soil. Soil Science 181:3/4 DOI: 10.1097/ SS.0000000000000150.

Porras-Alfaro, A., Herrera, J., Natvig, D.O., and Sinsabaugh, R.L. 2007. Effect of long-term nitrogen fertilization on mycorrhizal fungi associated with a dominant grass in a semiarid grassland. Plant Soil 296 (1-2):65-75.
Questad, E.J. and Foster, B.L. 2007. Vole disturbances and plant diversity in a grassland metacommunity. Oecologia 153:341-351.

Ruggiero, N. and Kral, G. L. 2018. Prescribed cattle grazing as a tool for native plant management: Lessons from the Tualatin River basin, Oregon. Journal of Soil and Water Conservation 73:74A-78A.

Schneider, S., Steeves, R., Newmaster, S., and MacDougall, A.S. 2017. Selective plant foraging and the top-down suppression of native diversity in a restored prairie. Journal of Applied Ecology 54:1496-1504.

Seastedt, T.R., Briggs, J.M., and Gibson, D.J. 1991. Controls of nitrogen limitation in tallgrass prairie. Oecologia 87:72-29.

Soons, M.B., Hefting, M.M., Dorland, E., Lamers, L.P., Versteeg, C., and Bobbink, R. 2017. Nitrogen effects on plant species richness in herbaceous communities are more widespread and stronger than those of phosphorus. Biological Conservation 212B:390-397.

Sousa, W.P. 1984. The role of disturbance in natural communities. Annual Review of Ecology and Systematics 15:353-391.

Timm, R. M., Pisani, G. R. and Slade, N. A. 2015. Mammals of Kansas. http://kufs.ku.edu/media/ kufs/libres/mammals_of_kansas.

U.S. Climate Data. n.d. "Climate Lawrence - Kansas and Weather Averages Lawrence." Accessed July 16, $2018 \mathrm{https}: / /$ www.usclimatedata.com/climate/ lawrence/kansas/united-states/usks0319.

Verdouw, H., Van Echiteld, C.J.A., and Dekkers, E.M.J. 1978. Ammonia determination based on indophenol formation with sodium salicylate. Water Research 12:399-402.

Vitousek, P. 1982. Nutrient cycling and nutrient use efficiency. American Naturalist 119:553-572.

Whicker,A.D. and Detling, J.K. 1988. Ecological consequences of prairie dog disturbances. BioScience 38:778-785.

Yoshihara, Y., Ohkuro, T., Buuveibaatar, B., and Jamsran, U. 2010. Spatial pattern of grazing affects influence of herbivores on spatial heterogeneity of plants and soils. Oecologia 162:427-434. 